Resting metabolic rate and thermic effects of a sucrose-sweetened soft drink ...

Edmund T S Li: Louisa B Y Tsang; Susan S H Lui

Canadian Journal of Physiology and Pharmacology; Jul 1999; 77, 7; ProQuest Medical Library

pg. 544

544

\title{
Resting metabolic rate and thermic effects of a sucrose-sweetened soft drink during the menstrual cycle in young Chinese women
}

\author{
Edmund T.S. Li, Louisa B.Y. Tsang, and Susan S.H. Lui
}

\begin{abstract}
The resting metabolic rate (RMR) and thermic effects (TEF) of a sucrose-sweetened soft drink in a group $(n=19)$ of ovulating young Chinese women were determined by indirect calorimetry in the midfollicular and midluteal phases of the menstrual cycle. Urinary luteinizing hormone surge was used to confirm ovulation. The RMR was measured twice in each phase and found to be similar $(F(1,18)=0.863)$ across the follicular $(5018 \mathrm{~kJ} / 24 \mathrm{~h})$ and the luteal $(5098 \mathrm{~kJ} / 24 \mathrm{~h})$ phases. Within each phase and on separate days, subjects were given water (280 $\mathrm{mL})$ or sucrosesweetened soft drink (539 kJ). Soft drink, but not water, consumption increased energy expenditure over a period of $45 \mathrm{~min}$. Compared with the follicular phase, a small but significant increase in TEF $(\mathrm{kJ} / 45 \mathrm{~min})$ was observed in the luteal phase $(t=2.434, p<0.05)$. Energy expenditure after drinking the soft drink, however, was similar in the two phases. RMR was positively correlated with TEF $(r=0.613, p<0.01)$ and net TEF $(r=0.648, p<0.005)$ in the luteal but not the follicular phase. In ovulating women, the thermic effect of sucrose is influenced by the phase of the menstrual cycle.
\end{abstract}

Key words: menstrual cycle, resting metabolic rate, thermic effect of food, sucrose, Chinese women.

\begin{abstract}
Résumé : La taux métabolique au repos (TMR) et l'effet thermique (TEF) d'une boisson gazeuse sucrée avec du saccharose ont été déterminés par calorimétrie indirecte, à mi-temps des phases lutéales et folliculaires du cycle menstruel, chez un groupe $(n=19)$ de jeunes femmes chinoises. L'afflux d'hormone lutéinisante urinaire a été utilisé pour confirmer l'ovulation. Le TMR, mesuré deux fois au cours de chaque phase, s'est révélé similaire $(F(1,18)=$ $0,863)$ dans les phases lutéale $(5098 \mathrm{~kJ} / 24 \mathrm{~h})$ et folliculaire $(5018 \mathrm{~kJ} / 24 \mathrm{~h})$. Durant chaque phase, lors de jours distincts, les sujets ont bu de l'eau $(280 \mathrm{~mL})$ ou une boisson gazeuse sucrée avec du saccharose ( $539 \mathrm{~kJ})$. La consommation de boisson gazeuse. mais non d'eau, a augmenté la dépense énergétique pendant une période de 45 min. Une augmentation faible mais significative de le TEF de la nourriture $(\mathrm{kJ} / 4.5 \mathrm{~min})$ a été observée dans la phase lutéale $(t=2,434, p<0,05)$ par comparaison à la phase folliculaire. Toutefois, après liı consommation de boisson gazeuse. la dépense énergétique a été similaire dans les deux phases. Le TMR a été corrélé positivement avec le TEF $(r=0.613$, $p<0,01)$ et le TEF net $(r=0,648 . p<0,005)$ dans la phase lutéale mais pas dans la phase folliculaire. Chez les femmes ovulant. l'effet thermique du saccharose est influencé par la phase du cycle menstruel.
\end{abstract}

Mots clés : cycle menstruel, taux métabolique au repos, effet thermique de la nourriture, saccharose. femmes chinoises.

[Traduit par la Rédaction]

\section{Introduction}

Energy expenditure across the menstrual cycle has been the subject of many investigations. Compared with the follicular phase, higher total energy expenditures (Webb 1986) and sleeping metabolic rates (Bisdee et al. 1989; Meijer et al. 1992) have been reported in the luteal phase; data on the resting metabolic rate (RMR) are inconclusive. Whereas Solomon et al. (1982), Das and Jana (1991), Lariviere et al. (1994), and Melanson et al. (1996) found a

Received December 7, 1998.

E.T.S. Li ${ }^{1}$ and L.B.Y. Tsang. Food and Nutritional Science Program. Department of Zoology. University of Hong Kong. Pokfulam Road, Hong Kong SAR, PRC.

S.S.H. Lui. Dietetic Department, Haven of Hope Hospital, Tseung Kwan O. Hong Kong.

${ }^{1}$ Author to whom all correspondence should be addressed (e-mail: etsli@hkucc.hku.hk . higher basal metabolic rate in the luteal phase, this phenomenon was not observed by Weststrate (1993), Piers et al. (1995), and Tai et al. (1997).

Factors that influence RMR may also influence the thermic effect (TEF) of food (also called diet-induced thermogenesis), another component of daily energy expenditure. Although Weststrate (1993) and Melanson et al. (1996) did not observe a menstrual cycle effect, Piers et al. (1995) reported a higher TEF in the luteal phase and Tai et al. (1997) reported a lower one in the luteal phase. In these earlier studies, test meals with varying carbohydrate, protein, and fat contents were used. Although the energy content of a meal is the major determinant of TEF (Kinabo and Durnin 1990), studying the effect of a single macronutrient, such as carbohydrate, is still warranted because menstrual periodicity does impact glucose metabolism (Jarrett and Graver 1968; Diamond et al. 1989) and the intake of energy (Lissner et al. 1988; Barr et al. 1995; Li et al. 1999), carbohydrate (Dalvit-McPhillips 1983; Johnson et al. 1994; L.i et al. 1999), and sugar-containing 
beverages (Fong and Kretsch 1993). In the present study the RMR and thermic effect of carbohydrate, in the form of a sucrose-sweetened soft drink, were examined in a group of young women during the midfollicular and midluteal phase of their menstrual cycle.

\section{Methods}

\section{Subjects}

Female university students of Chinese origin, 19--24 years old, were recruited through advertisements on campus notice boards. They did not use oral contraceptives and experienced regular menstrual cycles with lengths between 21 and 35 days. They were in good health with no history of eating disorders. None of them had been clinically diagnosed with premenstrual syndrome. A total of 26 students were recruited and 19 completed the study. Five subjects dropped out of the study because of illness and time conflicts. Two subjects did not complete the study because of anovulatory menstrual cycles. Each subject was fully informed about the nature and purpose of the study before giving written consent. The protocol was approved by the university ethics committee.

\section{Experimental design}

The midfollicular phase was designated as days 6 to 10 after menses onset (confirmed by telephone with the researcher). The midluteal phase was from days 6 to 10 after ovulation. which was confirmed by self-administered urinary luteinizing hormone (LH) surge tests (Clearplan. Unipath Ltd.). Ovulation was considered to have occurred 1 day after the appearance of the LH surge. According to the manufacturer, this monoclonal antibody-based test kit is more than $98 \%$ accurate in detecting the surge.

A repeated-measures design was used. All subjects were required to come to the laboratory four times, twice in each phase within the designated time frame. Resting metabolic rate was measured on all four occasions. Within each phase, TEF after water and soft drink was monitored on separate days. Half of the subjects had their first set of measurements taken in the follicular phase and half during the luteal phase. Thus, those subjects who started their measurements in the follicular phase had all measurements completed in the same cycle. For those who started their measurements in the luteal phase, data on the follicular phase were obtained from the following menstrual cycle. All measurements were performed in the morning after subjects fasted overnight for $10-12 \mathrm{~h}$. Some subjects stayed at the dormitory and arrived at the laboratory on foot. To minimize variability in physical activity levels prior to the measurements, commuting students were provided a taxi ride to the main gate of the university on measurement days. Upon arrival, they were asked to void and their body weights (dress without shoes, to the nearest $0.1 \mathrm{~kg}$ ) were taken using a digital balance (Seca 707 ). Height was measured to the nearest $0.1 \mathrm{~cm}$ by a stadiometer (Seca 220). Subjects were then instructed to lay supine on an easy chair for at least $30 \mathrm{~min}$ and no more than $40 \mathrm{~min}$. A light blanket was placed on top of the body. Indirect calorimetry was performed and with the use of a ventilated hood gaseous exchange was measured for $30 \mathrm{~min}$. The RMR of that day was estimated using the average energy expenditure of the last $10 \mathrm{~min}$ and extrapolated to kilojoules per 24 hours. With the ventilated hood still in place, subjects drank $280 \mathrm{~mL}$ of water (Watson's ${ }^{\mathrm{Ts}}$, Watson Industries Ltd. Hong Kong) or an equal volume of a sucrosesweetened soft drink (Sprite ${ }^{\text {in) }}$. The Coca-Cola Company, Hong Kong) through a straw within 3 min. Water and soft drink were assigned randomly between the two trial days within a phase. After the drink, energy expenditure (post-drink energy expenditure (PEE)) was monitored for an additional 45 min. Our preliminary results indicated that increases in energy expenditure peaked at
30 min post-drink. Accordingly, peak PEE was used to estimate the thermic effect of the drink. The delta peak has been shown to correlate significantly with diet-induced thermogenesis (over $345 \mathrm{~min}$ ) (Dabbech et al. 1994).

\section{Experimental drink}

The carbohydrate load was delivered in the form of a sucrosesweetened soft drink. In a pilot test, most subjects selected Sprite ${ }^{\mathrm{TM}}$ over several non-caffeine-containing carbonated and noncarbonated beverages as their choice of the experimental drink. They also picked a volume $(280 \mathrm{~mL}, 539 \mathrm{~kJ})$ that is less than in a standard aluminum can $(355 \mathrm{~mL})$. They felt that this volume did not induce a strong urge to void within the measurement period. The soft drink was degassed for $2 \mathrm{~h}$ prior to consumption.

\section{Indirect calorimetry}

Energy expenditure was measured by indirect calorimetry with an open circuit, computerized, ventilated hood system (SensorMedics 2900): SensorMedics Corp, Anaheim, Calif.). This ventilated hood system has a transparent semi-ellipsoidal bubble type canopy with an air inlet on top and an air outlet at the bottom. The latter was connected to a dilution pump via a mixing chamber. The total stream flow was measured by the flow meter. A small sample of air $\left(250 \mathrm{~cm}^{3} / \mathrm{min}\right)$ was taken from the mixing chamber for minute to minute measurement of $\mathrm{O}_{2}$ and $\mathrm{CO}_{2}$ concentration. Oxygen concentration was measured by a zirconium $\mathrm{O}_{2}$ analyzer and carbon dioxide concentration was analyzed by an infrared $\mathrm{CO}_{2}$ analyzer. The gas analyzers were calibrated with standard gases (span 1 gases were $25.95 \%$ oxygen with the balance nitrogen; span 2 gases were $16 \%$ oxygen. $4.14 \%$ carbon dioxide, with the balance nitrogen) (Hong Kong Oxygen Ltd.). Rates of oxygen consumption $\left(V_{\mathrm{O}_{2}} \cdot \mathrm{mL}^{-1} \cdot \mathrm{min}^{-1}\right)$ and carbon dioxide production $\left(V_{\mathrm{CO}_{2}} \cdot \mathrm{mL}^{-1} \cdot \mathrm{min}^{-1}\right)$ at standard temperature. pressure, and dryness were calculated from continuous measurement of the $\mathrm{O}_{2}$ and $\mathrm{CO}_{2}$ concentrations in inspired and expired air by a built-in computer program.

\section{Calculation of energy expenditure}

During measurement periods. raw data were processed on a minute to minute basis. Energy expenditure $(\mathrm{kJ})$ was calculated using the equation of Weir ( 1949 ). RMR was expressed as kilojoules per $24 \mathrm{~h}$. The time al which subjects started to drink was 0 min. To demonstrate a change in energy expenditure over time, energy expenditure was expressed as PEE at nine time points. Each time point represented the mean of the previous $5 \mathrm{~min}(\mathrm{~kJ} / \mathrm{min})$. Energy expenditure after soft drink consumption $\left(\mathrm{PEE}_{\mathrm{sd}}\right)$ was the cumulative energy expenditure $(k J)$ after consumption of Sprite with the RMR extrapolated over a period of $45 \mathrm{~min}$. TEF was calculated as the (i) delta peak $(\mathrm{kJ} / \mathrm{min})$, i.e., the peak PEE after soft drink consumption minus the RMR of that day; (ii) cumulative increase in energy expenditure $(\mathrm{kJ} / 45 \mathrm{~min})$ above the $R M R$, i.e.. $P E E_{\mathrm{sd}}$ minus RMR; (iii) a percentage of the energy content of the soft drink, i.e., TEF ( $\mathrm{kJ} / 45 \mathrm{~min}$ ) divided by $539 \mathrm{~kJ}$ times 100 ; and (iv) net TEF (kJ/45 min), which was the net increase above the value obtained after the ingestion of water, i.e.. TEF after soft drink consumption minus TEF after water consumption.

\section{Statistical analysis}

Results are expressed as means \pm SD. Statistical analysis were performed using SPSS for Windows (version 6.0. SPSS Inc., Chicago). For RMR comparisons, a two-way ANOVA with repeated measures was used (two phases and two trials per phase). To demonstrate the increase in energy expenditure after consumption of the soft drink and a possible difference between cycle phases, a three-way ANOVA with repeated measures was used to analyze the PEE and TEF values (two phases, two types of drinks per phase, and nine 
Table 1. Subject characteristics.

\begin{tabular}{lll}
\hline Characteristic & Mean \pm SD & Range \\
\hline Age (years) & $21.3 \pm 1.2$ & $19-24$ \\
Duration of menses (days) & $5.6 \pm 0.7$ & $4-6$ \\
Length of menstrual cycle (days) & $31.1 \pm 1.9$ & $27-34$ \\
Weight $(\mathrm{kg})$ & $49.0 \pm 3.7$ & $42.3-55.9$ \\
Height $(\mathrm{cm})$ & $159 \pm 4.7$ & $151.5-169.5$ \\
BMI $\left(\mathrm{kg} / \mathrm{m}^{2}\right)^{a}$ & $19.5 \pm 1.5$ & $17.8-24.2$ \\
Fat $(\%)^{b}$ & $22.4 \pm 3.5$ & 16 to 29 \\
\hline
\end{tabular}

Note: $n=19$

${ }^{a} \mathrm{BMI}$, body mass index.

${ }^{b}$ Determined by bioelectrical impedance analysis (Spectrum II Analyzer, RJL Systems) once in each phase.

Table 2. Resting metabolic rates grouped by menstrual cycle phase and trial sequence.

\begin{tabular}{lll}
\hline & Follicular phase $(\mathrm{kJ} / 24 \mathrm{~h})$ & Luteal phase $(\mathrm{kJ} / 24 \mathrm{~h})$ \\
\hline Trial 1 & $5010 \pm 432$ & $5117 \pm 478$ \\
Trial 2 & $5026 \pm 415$ & $5078 \pm 426$ \\
Within-subject CV & $3.9 \%(0.5-8.6)$ & $3.8 \%(0.2-10.2)$ \\
\hline Note: Values are means + SD for $n=19$. The results of the two-way ANOVA with repeated measures were as
\end{tabular}

Note: Values are means $\pm \mathrm{SD}$ for $n=19$. The results of the two-way ANOVA with repeated measures were as follows: $F(1,18)=0.863, p=0.367$ for the phase effect, $F(1,18)=0.165, p=0.693$ for the trial effect, and

$F(1,18)=1.154, p=0.297$ for the phase $\times$ trial effect.

time points per drink). As well, phase comparisons based on cumulative data were determined by paired $t$ tests. Statistical significance was accepted at $p<0.05$

\section{Results}

The subjects physical characteristics are shown in Table 1. Their body weight and body fat content remained stable over the study period. Relative to the body weight at the midfollicular phase $(49.1 \mathrm{~kg})$. mean change in the midluteal phase was $0.0 \pm 0.7 \mathrm{~kg}$ with a range of $+1.3 \mathrm{to}-1.3 \mathrm{~kg}$.

The two-way ANOVA with repeated measures indicated that RMR in the midfollicular phase (mean of two trials was $5018 \pm 387 \mathrm{~kJ} / 24 \mathrm{~h}$ ) was similar to that in the midluteal phase $(5098 \pm 420 \mathrm{~kJ} / 24 \mathrm{~h})$. As shown in Table 2 , there was no indication that RMR measured in the second trial within the same cycle phase differed from the first.

PEE values for the two cycle phases are shown in Fig. 1. The three-way ANOVA with repeated measures indicated significant effects for drink $(F(1,18)=99.30 . p<0.0001)$ and time $(F(8,144)=10.51, p<0.001)$ but not for phase $(F(1,18)=3.70, p=0.071)$. $\mathrm{PEE}_{\mathrm{sd}}$ during the $45 \mathrm{~min}$ after the soft drink consumption $\mathrm{u}$ as similar between the two cycle phases (Table 3 ).

The temporal changes in TEF after soft drink consumption and water consumption are shown in Fig. 2. The threeway ANOVA with repeated measures indicated significant effects of phase $(F(1,18)=160.31, p=0.001)$, drink $(F(1,18)=5.04, p=0.05)$. and time $(F(8,144)=10.18, p=$ $0.001)$. TEF after soft drink consumption peaked between 25 and $35 \mathrm{~min}$. Peak TEF $(\mathrm{kJ} / \mathrm{min})$ and the cumulative effect (kJ/45 min) after soft drink consumption in the luteal phase were higher than that in the follicular phase $t=3.59, p<$ 0.005 and $t=2.434, p<0.05$, respectively) (Table 3). Net TEF (soft drink minus water). however, was not different between the two phases $(t=1.211)$.
A relationship between thermogenesis and RMR is established in the luteal, but not the follicular phase. The correlation coefficient ( $r$ ) for TEF and RMR in the luteal phase and follicular phase was $0.613(p<0.01)$ and 0.378 , respectively. The plot of net TEF against RMR is shown in Fig. 3.

\section{Discussion}

This study demonstrated that ovulating women have similar resting metabolic rates in the midfollicular and midluteal phases of the menstrual cycle. In these subjects, thermic effect of food was easily detected after the consumption of a sucrose-sweetened sofit drink. A small but significant increase in TEF was detected in the luteal phase.

The study of menstrual periodicity and energy expenditure has spanned more than three-quarters of a century (Wiltshire 1921; Wakeham 1923) and continues to generate controversial results. A higher RMR in the luteal phase, compared with the follicular phase, has been demonstrated by several research groups. The magnitude of difference, however, is highly variable, ranging from a mere $80 \mathrm{~kJ} / 24 \mathrm{~h}$ (Melanson et al. 1996) to as much as $1500 \mathrm{~kJ} / 24 \mathrm{~h}$ (Solomon et al. 1982). In the latter study, subjects were confined to a metabolic ward for a prolonged period with their diet precisely controlled. While this approach allows rigorous measures in the experimental condition, the opportunity for individuals to self-regulate energy balances via changes in food intake and (or) activity level was curbed. In contrast, subjects in the present study were free-living and on a self-selected diet. Under these experimental conditions, RMR did not differ in the follicular and luteal phases. This result is in keeping with those studies using a similar experimental design (Weststrate 1989; Piers et al. 1995: Diffey et al. 1997). Recently, Tai et al. (1997) also reported a stable RMR at four different times in the menstrual cycle.

The resting metabolic rate of our subjects averaged (four measurements) $5058 \mathrm{~kJ} /$ day. This value is consistent with 
Fig. 1. Post-drink energy expenditure (PEE) after soft drink (ש) or water ( consumption in the follicular (top panel) and luteal (bottom panel) phases of the menstrual cycle. Subjects started to drink at $0 \mathrm{~min}$ and finished at $3 \mathrm{~min}$. Changes in energy expenditure over time were expressed at nine time points. Each time point represented the mean of the previous $5 \mathrm{~min}$. Values are means \pm SD for $n=19$.
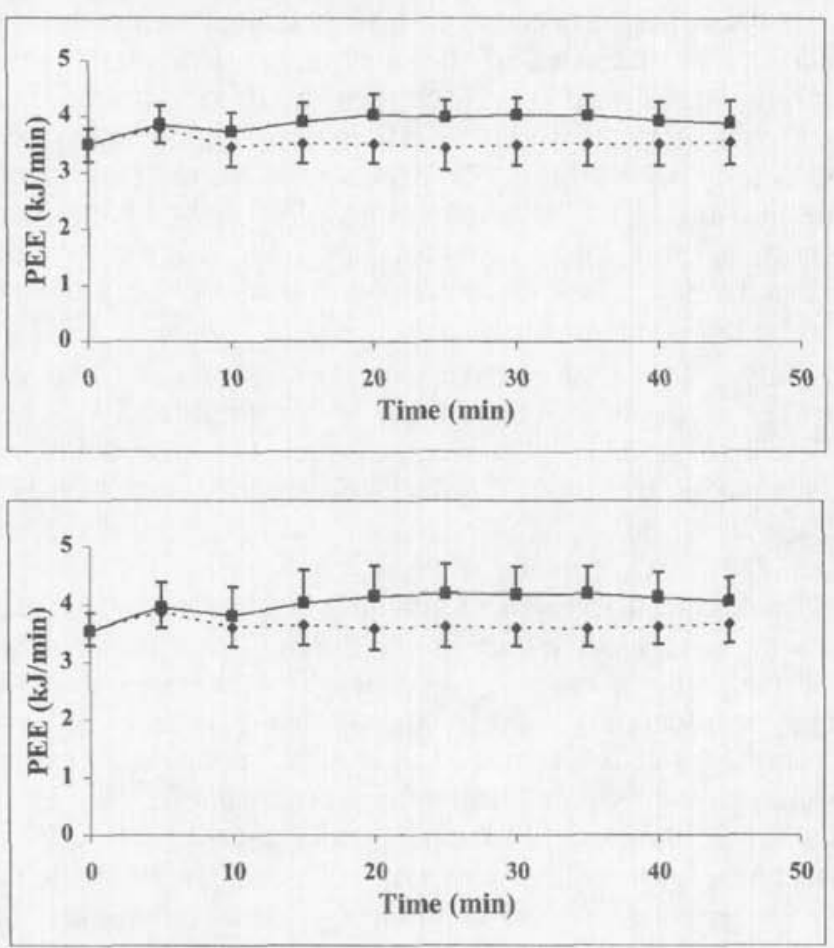

Fig. 2. Time course of the thermic effect of drinking a sucrosesweetened soft drink (E) or water ( ) in the follicular (top panel) and luteal (bottom panel) phases of the menstrual cycle. Changes in TEF over time were expressed at nine time points. Each time point represented the mean of the previous $5 \mathrm{~min}$. Values are means $\pm \mathrm{SD}$ for $n=19$.
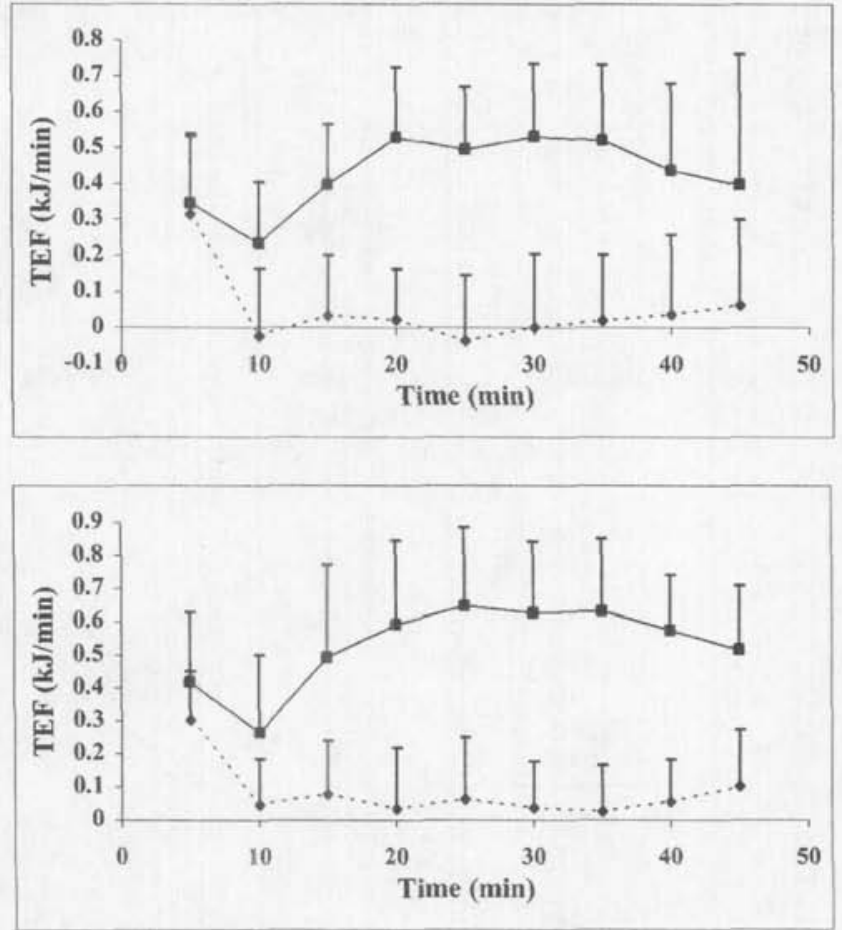

Table 3. Post-drink energy expenditure in the follicular and luteal phases.

\begin{tabular}{lll}
\hline Energy expenditure & Follicular & Luteal \\
\hline $\mathrm{PEE}_{\text {sd }}(\mathrm{kJ} / 45 \mathrm{~min})$ & $176.5 \pm 16.3$ & $182.5 \pm 19.0$ \\
$\mathrm{PEE}_{\text {water }}(\mathrm{kJ} / 45 \mathrm{~min})$ & $158.5 \pm 16.6$ & $163.6 \pm 15.2$ \\
$\mathrm{TEF}$ & & \\
$\quad$ (delta peak, $\mathrm{kJ} / \mathrm{min})$ & $0.60 \pm 0.17$ & $0.74 \pm 0.20^{a}$ \\
$(\mathrm{~kJ} / 45 \mathrm{~min})$ & $19.5 \pm 7.6$ & $23.9 \pm 7.9^{a}$ \\
$(\%$ of soft drink energy) & $3.6 \pm 1.4$ & $4.4 \pm 1.5^{a}$ \\
(Net TEF, $\mathrm{kJ} / 45 \mathrm{~min})$ & $17.5 \pm 9.4$ & $20.3 \pm 7.4$ \\
\hline
\end{tabular}

Note: Values are means \pm SD for $n=19$

${ }^{a}$ Significantly different from that of follicular phase, $p<0.05$ using a paired $t$-test.

the $5089 \mathrm{~kJ} /$ day predicted by the WHO equation (1985) for women 18-30 years old. When metabolic rate was estimated using the predictive equation of Liu et al. (1995) for Chinese women. a mean difference of $71 \mathrm{~kJ} /$ day was obtained between our measured values and the predicted values. These measured and predicted values, however, are $7-10 \%$ less than those predicted by the popular Harris-Benedict equation (1919), which has been found to overestimate metabolic rate (Daly et al. 1985). In the present study, intraindividual variation $(\mathrm{CV})$ of RMR measurements within a particular cycle phase was slightly less than $4 \%$ (Table 2). However, the overall $\mathrm{CV}$ increased to $5.1 \%$ when the RMR of both $\mathrm{cy}$ cle phases were pooled. The data suggest that fluctuations in RMR are slightly bigger across cycle phases. Our observed $\mathrm{CV}$ values are in general agreement with those reported by others, which ranged from $3.8 \%$ (Tai et al. 1997) to $7.6 \%$ (Piers et al. 1995). A gender difference is clear. Much smaller variations ( $\mathrm{CV}<2 \%$ ) were observed in men (Soares et al. 1989; Dabbech et al. 1994). Consistent with previous reports (Weststrate 1993; Chiplonkar et al. 1992; Piers et al. 1995; Diffey et al. 1997), the intraindividual $\mathrm{CV}$ of the RMR was much less than that of interindividual CV $(8.4 \%)$. The large interindividual variation is attributed to differences in body mass and hormonal influences (Durnin 1996). Phytoestrogens in soy products (Lien and Lien 1996) of a typical Chinese diet might play a role as these compounds have estrogenic or anti-estrogenic activity.

Although the energy content of the soft drink is only modest $(538 \mathrm{~kJ})$, a clear-cut TEF was observed in both cycle phases. On a per minute basis, mean TEF $(0.48 \mathrm{~kJ} / \mathrm{min})$ is 
Fig. 3. The correlation between RMR and net TEF in the follicular (top panel) and luteal (bottom panel) phases of the menstrual cycle.
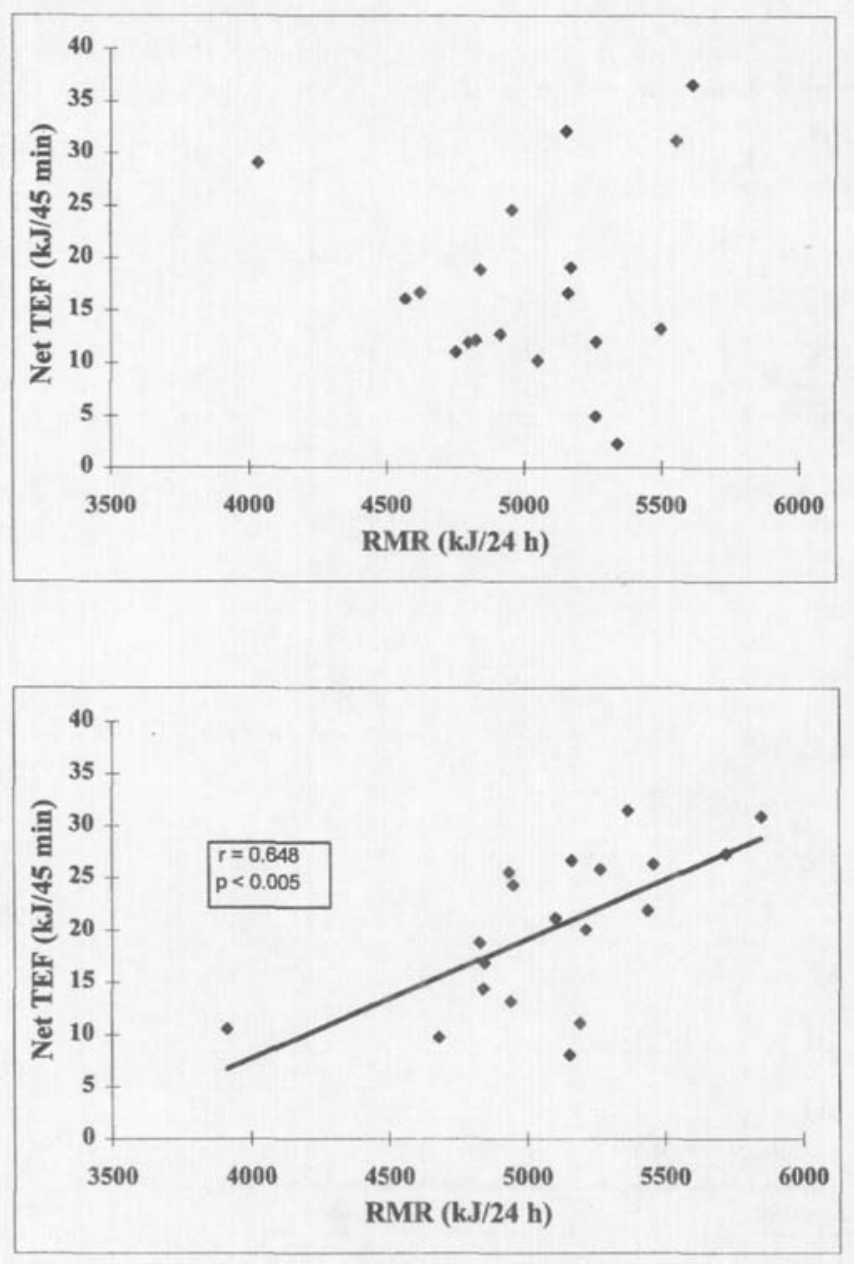

similar to that reported by Piers et al. (1995) but is much lower than that reported by Tai et al. (1997). Since the latter studies used mixed meals, at direct comparison might not be appropriate. Also of interest is that Swaminathan et al. (1985) reported a mean value of $0.523 \mathrm{~kJ} / \mathrm{min}$ during the period $30-120 \mathrm{~min}$ after the consumption of glucose $(1.67 \mathrm{MJ})$. The slightly larger value might be related to the higher energy content of the test meal and the fact that $27 \%$ of their subjects were men.

In most earlier studies, follicular data were collected first, followed by luteal data in a sequential manner. To avoid possible systematic error such as training effect (Soares et al. 1989; Piers et al. 1992), our subjects' first measurements were randomized between the two cycle phases. Thus, in nine subjects the phase comparisons were based on betweencycle data. Nevertheless, analyses of RMR and TEF were not influenced by values derived from within-cycle or betweencycle data (data not shown). We acknowledged that the TEF study would benefit from repeated measurements and a longer duration. When designing the experiment, we considered the advantages of replicating the effect of the sucrose drink within each cycle phase (Weststrate 1993). If this design had been followed, we would not have been able to monitor en- ergy expenditure after water consumption (so that net TEF could be estimated) because most of the subjects declined to attend more than two measurements per cycle phase. Thus, we aimed to compensate for this weakness by having a large sample size (the majority of similar studies had less than 10 subjects). It is well known that TEF might last for more than $6 \mathrm{~h}$ (Reed and Hill 1996). We elected to use a rather short assessment period because the energy content of the drink is much lower than that of the commonly used mixed meals and the delta peak approach was used to estimate TEF (Dabbech et al. 1994). Using this strategy, the thermic effect was easily detected (Fig. 2). Because the duration was short, the measured TEF only represented $4 \%$ of the energy content of the soft drink (Table 3). This value is lower than the 5.2 and $7.3 \%$ values reported by Tai et al. (1997) and Piers et al. (1995), respectively.

Only a few studies have examined the impact of menstrual periodicity on TEF and the results are mixed. Whereas Weststrate (1993) and Melanson et al. (1996) reported no cycle phase effect. Piers et al. (1995) reported increased TEF in the luteal phase, and Tai et al. (1997) reported decreased TEF. The discrepancies were rationalized on the basis of methodological differences, including experimental design, sample size, meal composition, duration of measurement, and variability in thermic responses. To eliminate one of the many confounding factors, we elected to use a sucrosesweetened soft drink instead of a mixed meal. A menstrual cycle phase effect on TEF was revealed. That is, the TEF or delta peak after soft drink consumption increased by $23 \%$ in the luteal phase. This magnitude is comparable with the $18.5 \%$ reported by Piers et al. (1995). In the latter study, intermittent TEF was monitored for a duration of $5 \mathrm{~h}$ after the ingestion of a mixed meal. Based on these data, it could be argued that a TEF difference of up to $100 \mathrm{~kJ} /$ day might occur and could contribute to the daily difference in total energy expenditure between the two phases (Webb 1986). Because we also monitored energy expenditure after water consumption, we were able to estimate the net metabolic impact of the soft drink (net TEF). Thus, thermogenesis attributable to the energy content of sucrose alone was not affected by the phase of the menstrual cycle (Table 3 ).

This study also provides evidence to support an effect of the menstrual cycle on energy metabolism. Further analyses of the present data revealed a positive correlation between the RMR and TEF in the luteal but not the follicular phase. The cycle phase difference was even more apparent when RMR was correlated with net TEF (Fig. 3). These results suggest that the internal milieu during the luteal phase allows mechanism(s) influencing metabolic rate and thermogenesis to work in some coordinated manner. The relative importance of various physiological factors in defining the internal milieu deserves further investigation.

As mentioned earlier, there has been no systematic study on the thermic effect of individual macronutrients as a function of menstrual cycle phase. This has led to difficulties in explaining the varying results obtained from those studies using mixed meals. Data derived from the present study suggest that when energy is derived from carbohydrate only, TEF is higher in the luteal phase than in the follicular phase. Accordingly, it would be useful to determine whether the 
phase effect is macronutrient specific. The mechanism(s) for this cycle phase effect remains elusive. Earlier studies had attempted to rationalize the difference on the basis of glucose utilization (Diamond et al. 1989; Jarrett and Graver 1968), insulin sensitivity (Astrup et al. 1992), gastric emptying rate (Wald et al. 1981), and sympathetic tone (Piers et al. 1995). Simultaneous monitoring of one or more of these parameters and metabolic rate in future studies should help clarify the physiological basis of TEF in different phases of the menstrual cycle.

In conclusion, similar RMR was obtained during the mid phases of the menstrual cycle in ovulating women. In comparison with that in the follicular phase, TEF after soft drink consumption was higher in the luteal phase. In the luteal phase, TEF also correlated positively with RMR. The biological implications of a differential TEF after carbohydrate consumption in the luteal and follicular phases remain to be determined. Because the consumption of carbohydrate and fat is higher in the luteal phase (Li et al. 1999), further studies on menstrual cycle, TEF, and feeding behavior are warranted.

\section{Acknowledgement}

This research was supported by a committee on research and conference grant. University of Hong Kong.

\section{References}

Astrup, A., Buemann. B., Christensen, N.J., Madsen, J.. Gluud, C., Bennett. P., and Svenstrup. B. 1992. The contribution of body composition, substrates, and hormones to the variability in energy expenditure and substrate utilization in premenopausal women. J. Clin. Endocrinol. Metab. 74: 279-286.

Barr. S.I. Janelle, K.C., and Prior. J.C. 1995. Energy intakes are higher during the luteal phase of ovulatory menstrual cycles. Am. J. Clin. Nutr. 61: 39-43.

Bisdee, J.T., James, W.P.T., and Shaw, M.A. 1989. Changes in energy expenditure during the menstrual cycle. Br. J. Nutr. 61: $187-199$.

Chiplonkar, S.A., Agte. A.A., Gokhale, M.K.. Kulkarni, V.V.. and Mane. S.T. 1992. Energy intake and resting metabolic rate of young Indian men and women. Indian J. Med. Res. Sect. B. 96: 250-254.

Dabbech. M.. Aubert, R., Apfeltaum. M., and Boulier, A. 1994. Reproducible measurement of postprandial energy expenditure in young healthy males. Am. J. Clin. Nutr. 60: 849-854.

Dalvit-McPhillips. S.P. 1983. The effect of the human menstrual cycle on nutrient intake. Physiol. Behav. 31: 209-212.

Daly. J.M.. Heymsfield, S.B., Head. C.A., Harvey, L.P., Nixon, D.W. Kaltzeff, H.. and Grossamn, G.D. 1985. Human energy requirements: overestimation by widely used prediction equation. Am. J. Clin. Nutr. 42: 1170-1174

Das. T.K.. and Jana. H. 1991. Basal oxygen consurnption during different phases of menstrual cycle. Indian J. Med. Res. Sect. B. 94: $16-19$

Diamond, M.P.. Simonson. D.C.. and DeFronzo, R.A. 1989. Menstrual cyclicity has a profound effect on glucose homeostasis. Fertil. Steril. 52: 204-208.

Diffey, B., Piers. L.S., Soares, M.J., and O'Dea, K. 1997. The effect of oral contraceptive agents on the basal metabolic rate of young women. Br. J. Nutr. 77: 853-862.
Durnin, J.V. 1996. Energy requirements: general principles. Eur. J. Clin. Nutr. 50(Suppl. 1): S2-S9.

Fong, A.K.H.. and Kretsch, M.J. 1993. Changes in dietary intake, urinary nitrogen. and urinary volume across the menstrual cycle. Am. J. Clin. Nutr 57: 43-46.

Harris, J.A., and Benedict. F.A. 1919. A biometric study of basal metabolism in man. Carnegie Institute of Washington, Washington, D.C. Publication No. 279.

Jarrett, R.J., and Graver, H.J. 1968. Changes in oral glucose tolerance during the menstrual cycle. Br. Med. J. 2: 528-529.

Johnson, W.G., Corrigan, S.A.A.. Lemmon. C.R., Bergeron, K.B., and Crusco, A.H. 1994. Energy regulation over the menstrual cycle. Physiol. Behav. 56: 523-527.

Kinabo, J.L., and Durnin, J.V.G.A. 1990. Thermic effect of food in man: effect of meal composition and energy content. Br. J. Nutr. 64: $37-44$

Lariviere, F.. Moussalli, R., and Garrel, D.R. 1994. Increased leucine flux and leucine oxidation during the luteal phase of the menstrual cycle in women. Am. J. Physiol. 267: E422-E428.

Li, E.T.S., Tsang, L.B.Y.. and Lui, S.S.H. 1999. Menstrual cycle and voluntary food intake in young Chinese women. Appetite. In press.

Lien, L.L., and Lien, E.J. 1996. Hormone therapy and phytoestrogens. J. Clin. Pharm. Ther. 21: 101-111.

Lissner, L., Stevens, J., Levitsky. D.A., Rasmussen, K.M., and Strupp, B.J. 1988. Variation in energy intake during the menstrual cycle: implications for food-intake research. Am. J. Clin. Nutr. 48: 956-962.

Liu, H.Y., Lu, Y.F., and Chen, W.J. 1995. Predictive equations for basal metabolic rate in Chinese adults: a cross-validation study. J. Am. Diet. Assoc. 95: 1403-1408.

Meijer, G.A.L., Westerterp, K.R., Saris, W.H.M., and ten Hoor. F. 1992. Sleeping metabolic rate in relation to body composition and the menstrual cycle. Am. J. Clin. Nutr. 55: 637-640.

Melanson. K.J.. Saltzman, E., Russell, R.. and Roberts, S.B. 1996. Postabsorptive and postprandial energy expenditure and substrate oxidation do not change during the menstrual cycle in young women. J. Nutr. 126: 2531-2538.

Piers, L.S., Soares, M.J. Makan. T., and Shetty, P.S. 1992 Thermic effect of a meal. 1. Methodology and variation in normal young adults. Br. J. Nutr. 67: 165-175.

Piers, L.S. Diggavi, S.N., Rijskamp, J., van Raaji, J.M.A., Shetty, P.S.. and Hautrast. J.G.A.J. 1995. Resting metabolic rate and thermic effect of a meal in the follicular and luteal phases of the menstrual cycle in well-nourished Indian women. Am. J. Clin. Nutr. 61: 296-302.

Reed, G.W., and Hill, J.O. 1996. Measuring the thermic effect of food. Am. J. Clin. Nutr: 63: 164-169.

Soares, M.J., Piers. L.S., Kraai. L.. and Shetty, P.S. 1989. Day-today variations in basal metabolic rates and energy intakes of human subjects. Eur. J. Clin. Nutr. 43: 465-472.

Solomon, S.J., Kurzer. M.S., and Calloway, D.H. 1982. Menstrual cycle and basal metabolic rate in women. Am. J. Clin. Nutr. 36: 611-616.

Swaminathan. R., Kings, R.F.G.J., Holmfield. J., Siwek. R.A.. Baker, M.. and Wales, J.K. 1985. Thermic effect of feeding carbohydrate, fat, protein and mixed meal in lean and obese subjects. Am. J. Clin. Nutr. 42: 177-181.

Tai, M.M., Castillo, P.F., and Pi-Sunyer. F.X. 1997. Thermic effect of food during each phase of the menstrual cycle. Am. J. Clin. Nutr. 66: $1110-1115$

Wald, A., van Thiel. D.H., Hoechstetter, L., Gavaler, J.S., Egler, K.M., Verm, R.. Sco1t. L., and Lester, R. 1981. Gastrointestinal 
transit: the effect of the menstrual cycle. Gastroenterology, 80: $1497-1500$.

Wakeham, G. 1923. Basal metabolic rate and the menstrual cycle. J. Biol. Chem. 56: 555-567.

Webb, P. 1986. 24-Hour energy expenditure and the menstrual cycle. Am. J. Clin. Nutr. 44: 61+619.

Weststrate, J.A. 1993. Resting metabolic rate and diet-induced thermogenesis: a methodological reappraisal. Am. J. Clin. Nutr. 58: $592-601$.
Weir, J.B. 1949. New methods for calculating metabolic rate with special reference to protein metabolism. J. Physiol. (London), 109: $1-9$.

Wiltshire, M. 1921. Some observation on basal metabolism in menstruation. Lancet, 2: 338-339.

WHO (World Health Organization). 1985. Energy and protein requirements. Report of a joint FAO/WHO/UNU Expert Consultation. WHO Technical Report Series No. 724. World Health Organization. Geneva. 